\title{
Integrating Emerging Technologies into Higher Education - The Future Perceptions
}

\author{
Janika Leoste ${ }^{1,}{ }^{*}$, Larissa Jõgi ${ }^{1}$, Tiia Õun ${ }^{1}$, Luis Pastor ${ }^{2}$, José San Martín López ${ }^{2}$ and Indrek Grauberg ${ }^{1}$ \\ 1 Tallinn University, Tallinn 10120, Estonia \\ 2 Universidad Rey Juan Carlos, Calle Tulipán, s/n, 28933 Móstoles, Madrid, Spain \\ * Correspondence: leoste@tlu.ee; Tel.: +372 5045081
}

\begin{abstract}
Emerging technologies have a potential future impact on the developments in higher education and teaching practices at the universities. The paper is based on the project "My future colleague robot" that aims to improve the competence of university teachers in the implementation of Emerging Technologies (ETs) in the teaching practices at the university. In this paper, we identified the strengths and weaknesses, opportunities and threats that are related to the adoption of two ETs, robotics and Artificial Intelligence (AI), in higher education. Additionally, we analyzed the perceptions of faculty about these ETs. The empirical data was collected using written essays from 18 university teachers and students. Deductive and inductive approaches with thematic analysis were used for the data analysis. The findings support the idea that previous experience related to ETs can support positive attitudes and the implementations of ET in university teaching. University teachers had optimistic expectations towards ETs accepting them as part of teaching practice development, while discussion about the negative effects of ETs was negligible.
\end{abstract}

Keywords: Emerging technologies; Educational Innovation; Artificial Intelligence; Robotics; Higher Education; Teaching Practices

\section{Introduction}

This paper is based on the results of the one-year international development project "My future colleague robot, a project conceived for raising and developing the university's teachers' competence in integrating Emerging Technologies (ETs), such as artificial intelligence and complex robots, to different higher education disciplines. The novelty character of these technologies is based not only on their originality, but on the possibilities of initiating new ways and approaches of doing something - for example, coordinating pedagogical activities, social interaction and knowledge construction in the educational process [1]. However, due to their innovative nature, ETs are mostly untested in real life situations, and their link to pedagogical approaches and activities in higher education is often insufficiently developed. As researchers, we were interested in how university teachers and their students envision the changes that ETs could cause in society in general, and particularly in their disciplines.

From a historic perspective, major technological changes have led society almost always towards making ever-increasing demands on education [2], with the latter trying to catch up the status quo of the social needs, newly created by ETs. Emerging technologies bring novel and fast growing approaches that have a potential future impact on actors, institutions and their interaction patterns within socio-economic domains, along with the associated knowledge production processes [3]. Scientific knowledge creates new opportunities and solutions that can enrich our lives, while at the same time can fuel disruptive waves of change in every sector. Unprecedented innovation in science and technology, especially in bio-technology and artificial intelligence, is raising fundamental questions about what it is to be human [4]. For these reasons, ETs typically have a broad impact on the people's everyday routines, allowing them to reshape their own relationship with the 
world and their perception of reality [5]. In the 21st century, ETs favor jobs with nonrepetitive nature, consisting of tasks that require thinking and in general require intellectual creativity [6]. In education, some ETs are considered crucial [7-8]:

- Artificial Intelligence (AI) can facilitate administrative tasks, provide students with adaptive learning environments, differentiated learning tools and feedback, even being perhaps able to completely replace human teachers. Together with Big Data, AI lays grounds for evidence-based education [9].

- Big Data (BD) involves large and complex datasets that are not easily managed by traditional methods [10]. BD facilitates various forms of analytics in education, such as learning analytics (a tool for monitoring student learning progress and for providing individualized guidance), wellbeing analytics (a promising tool for combating mental health related challenges), and curriculum analytics (a tool for analyzing which curriculum parts work well and which need improvement).

- Immersive and advanced visualization technologies, including Virtual Reality and Augmented Reality tools, which allow the cost-effective creation of specialized learning environments (e.g. for learning \& training in areas as diverse as medicine or space) that allows the recreation of an infinity of different scenarios and situations to complete conventional training.

- Robots, which can be used as: (a) learning tools for robotics (for teaching either robotbuilding and coding, or using robots in medicine, manufacturing, etc.); (b) engaging learning tools to support teaching other disciplines such as math and physics; (c) as peers and tutors when combined with artificial intelligence.

These ETs open up a variety of new opportunities in education. On the one hand, institutions can improve their administrative efficiency [8], cutting various costs in the process. Also, as learners will have more freedom to determine their own pace and location of learning, these technologies can support self-determined learning [11] and contribute to the shift from an instructor-led education to a learner-based educational environment [12]. On the other hand, these changes challenge the established ways of teaching. The ability of ETs to support curricula upgrades is an opportunity and obligation for the educational institutions in order to develop appropriate pedagogical approaches that support adopting new ways and policies for teaching and learning [12]. Even in the cases when educational institutions have already implemented some 21st century skills to their curricula, there is a need for developing systematic approaches, supported by appropriate pedagogies and assessment procedures [12]. This process is often obstructed by teachers' hesitance that has various origins [13]. In higher education it is necessary to evolve new technological developments and use them effectively to facilitate learning [14].

In this paper, we focus on the higher education context, and particularly, on two ETs, $\mathrm{AI}$ and robotics, for the following reason: The combination of android robots with advanced AI can result in machines that can be perceived as creatures similar to humans, having potential to intervene in, perhaps, all domains of human life. Proliferation of such machines may cause surfacing of new communication patterns that could be able to effectively connect people with AI driven robots. However, it could also cause people to reuse their existing communication patterns with robots, extending the ways of how we perceive and deal with machines. This in turn could even lead to extending some legal and moral rights that have been reserved to people to robots - with results that cannot be clearly predicted as of today.

\subsection{Artificial Intelligence and Robotics}

Robots are machines, designed to autonomously perform specific tasks. The purpose of a robot determines its appearance, intelligence and other characteristics. Robots are usually categorized by the following attributes [15]: (a) their operating environment - marine robots, space robots, etc.; (b) their interaction with users - autonomous, programmed, tele-operated or collaborative robots; (c) their physical characteristics - nano robots, exoskeletons, robotic arms, etc.; and (d) their primary purpose - self-driving cars, assembly line robots, robotic lawn mowers, etc. 
Due to advances in computing power, an increasing number of robots are being driven by AI, allowing robots to be used in areas where human intelligence is usually required [16] - for example, holding a conversation with people or making financial investments [17]. AI is considered to be weak when the robot merely imitates human behavior, or strong if the robot is able to learn from its previous experiences [18]. AI-driven robots are seen promising in many areas, from healthcare to manufacturing, due to them being precise, flexible, allowing reducing costs while saving energy and other resources [19]. Due to the existence of android robots, robotics in general is often perceived as a threat to people's jobs and way of life, as it is easier for a person to envision human-like robots with superhuman abilities to make the actual humans obsolete in the workplace and even in their private lives. However, the literature confirms that such hostile attitudes towards robots are subject to fade if people have a personal experience with robots [2021].

\subsection{Research Questions}

Due to their revolutionary impact, ETs tend to require fundamental changes in existing processes in order for the positive effects to be highlighted [22]. This characteristic can be problematic in education, as teachers are reported to start changing their teaching methods only after they have already acquired the necessary skills and knowledge to work with the new technologies [23]. In addition, teachers as knowledge workers tend to resist instructions and models from outside of their communities, viewing formal processes as annoying [24], instead leaning on their personal perception about the usefulness of the ETs in their teaching practices. Convincing teachers to accept and adopt novel technologies may require good understanding about the teachers' perspectives [10], as they are well familiar with the matters of pedagogy, teaching and learning, just like students are familiar with their indirect learning needs. Bringing a novel technology with its accompanying methods into existing teaching practices at the universities requires introduction of the technology to the teachers, gathering their feedback, and constructing an implementation plan that considers the needs of teachers. The current study was conducted at an Estonian university. Estonian students have been internationally known for their good PISA results. At the same time, it is criticized that learning in Estonian educational institutions is not sufficiently learner-centered and current professional education in higher education does not sufficiently support the development of students' future skills [25].

Using the examples of AI and robotics, the aim of this paper is to gain a deeper understanding of the university teachers' perceptions and points of view on ETs in their future lives, on ETs impact on the society in general and particularly on their disciplines and teaching practices. This is to contribute to developing a point of departure for programs that aim to integrate ETs into higher education. Using AI and robotics as the examples of ETs, we have formed the following research questions:

1. What are the strengths, weaknesses, opportunities and threats of proliferation of robots and AI, from the point of view of university teachers and students?

2. What are the perceptions of university teachers related to emerging technologies?

Next, we continue our paper by providing background information about the project "My future colleague robot" and then presenting the methodological framework of the research. To answer our research questions we present empirical results and discuss the analytical findings from the deductive and inductive analysis. Finally we present a collective story, which makes visible the voices of university teachers and conclude the paper with some suggestions for future research.

\section{Materials and Methods}

The project My Future Colleague Robot was conducted at Tallinn University from July 2020 to June 2021. One of the results of the project was Vision Book, which focused on the roles of ETs, especially on those of robotics and AI, in education and everyday life. The participants of the project (university teachers and their students) were asked to contribute to writing this book, stating their thoughts and assumptions, related to using robots 
and $\mathrm{AI}$ in higher education, using a freewriting approach [26]. For this, they had to write an essay or record a video about their vision on how ETs are going to be used in education and everyday lives in the future. The participants were given three months (from February 2021 to June 2021) to independently write and complete their submissions. Each contribution became a separate chapter in Vision Book.

The participating teachers and their students were teaching and learning at the university in different disciplines, had different academic positions and had agreed with the invitation to participate. The purposeful sample group was formed, consisting of 18 higher education teachers and students from different disciplines and generations. Final sample group $(\mathrm{N}=18)$ consists of 7 women and 11 men; 8 were from STEM disciplines, and 10 from the humanitarian and social disciplines. Based on the academic positions, the participants were professors (2), associate professors (4), lecturers (6), researchers (3), bachelor students (2), and a master student (1). None of the participants from the humanitarian and social disciplines had integrated ETs to their teaching practices before or during the development project.

Empirical data was collected from Vision Book chapters according to agreements made between the researchers and the members of the sample group. Written essays and transcriptions of recorded videos were coded using numbers in the same order as they were structured in Vision Book. Data analysis is based on interpretive paradigm [27]. For empirical analysis we used a combination of two approaches: "top down" - a deductive approach for the first research question and "bottom up" - an inductive approach for the second research question [28]. We used the inductive approach with thematic analysis [28], focusing on the common themes, also on variations of meanings in the empirical data. As researchers we were interested in how participants' described and understood a complex future phenomenon [29], related to ETs. Finally, based on findings from the thematic analyses we constructed a collective future story [30] and presented it in the final part of our paper.

In the analyzing process the following steps and procedures were used. First, the videos were transcribed and the empirical material together with data from essays were anonymized and coded using numbers (for instance, T1, T2, etc.). Based on the research question 1, we used four general categories of meaning: strengths, weaknesses, opportunities, threats, and created new subcategories, which appeared from the empirical material. The subcategories were held on as abstract level as possible in order to avoid several codes with a similar meaning that are difficult to encapsulate. Each subcategory was counted only once per text, if present. If the next text gave rise to a similar subcategory then before creating a new one, it was considered whether rephrasing an existing one would be a better option. The created subcategories and their occurrences were entered into data table (Table 1), creating a basis for the subsequent processing.

The coding and data analysis was conducted by two researchers. The agreement about codes was created via thorough discussions before, during and after the coding process, with the purpose of relaying the true representation of the meaning of the texts.

Based on the second research question, inductive thematic analysis was used. It was based on six steps and was done in order to understand perceptions of the university teachers related to ETs. The next steps were used: reading empirical material and searching for meanings; generating initial codes; searching for themes; reviewing and refining themes; defining common themes [28]. Finally, narrative coding of common themes for constructing the collective story was done [31] (p. 109), [32] using elements of inductive analysis and conceptual memos from two researchers. The collective story presents research data in the form of a dialogue between participants [30] and can be used to create immersive scenarios of the future that engage us as a scholar on an emotional and intellectual level [33]. To ensure the trustworthiness of data analysis and that the themes from analysis reflected the participants' voices, we used peer debriefing and returned several times to the raw data [34].

Table 1. Categories of meanings and subcategories. 


\begin{tabular}{|c|c|c|}
\hline Main categories & Subcategories & Occurrences \\
\hline \multirow{8}{*}{ Strengths } & Support people in their work & 17 \\
\hline & Support people in their private lives & 14 \\
\hline & Support learning & 12 \\
\hline & Are convenient to use & 7 \\
\hline & Are irreplaceable in some areas & 6 \\
\hline & Entertain people & 4 \\
\hline & Support students with special educational needs & 3 \\
\hline & Are cost-effective & 2 \\
\hline \multirow[t]{9}{*}{ Weaknesses } & People need training programs about ETs & 9 \\
\hline & People lack sufficient understanding about ETs & 8 \\
\hline & Are initially confusing & 5 \\
\hline & People are biased towards ETs & 4 \\
\hline & ETs are difficult for the general public & 2 \\
\hline & ETs can be costly & 2 \\
\hline & Legal aspects & 2 \\
\hline & ETs are difficult to integrate to education & 1 \\
\hline & Reliability problems & 1 \\
\hline \multirow[t]{9}{*}{ Opportunities } & Free people for other things, change of roles & 1 \\
\hline & Enhance people's abilities & 6 \\
\hline & Make new things possible & 5 \\
\hline & Allow social advances in community & 5 \\
\hline & Support transformation of teaching practices & 5 \\
\hline & Support kids with autistic or similar disorders & 2 \\
\hline & Save resources & 2 \\
\hline & Can increase equality and equity in education & 1 \\
\hline & Create new jobs & 1 \\
\hline \multirow[t]{5}{*}{ Threats } & Change labor roles and needs & 9 \\
\hline & Threaten social and emotional aspects (human way of life) & 8 \\
\hline & Replace humans & 7 \\
\hline & Can lead to wasting resources & 1 \\
\hline & Convert humans to robots & 1 \\
\hline
\end{tabular}

In the next section of our paper we present the results of empirical analysis, based on research questions.

\section{Results}

3.1. Strengths and Weaknesses, Opportunities and Threats of Implementing Emerging Technologies to Teaching Practices and Learning Process

Our first research question was: "What are the strengths, weaknesses, opportunities and threats of implementing emerging technologies to teaching practices and learning process, from the point of view of university teachers and students?" To answer this question, we first observed which of the four major categories of meaning were most represented in participants' contributions, by counting the occurrence of different subcategories (Figure 1) in the empirical material. Each subcategory was counted once. 


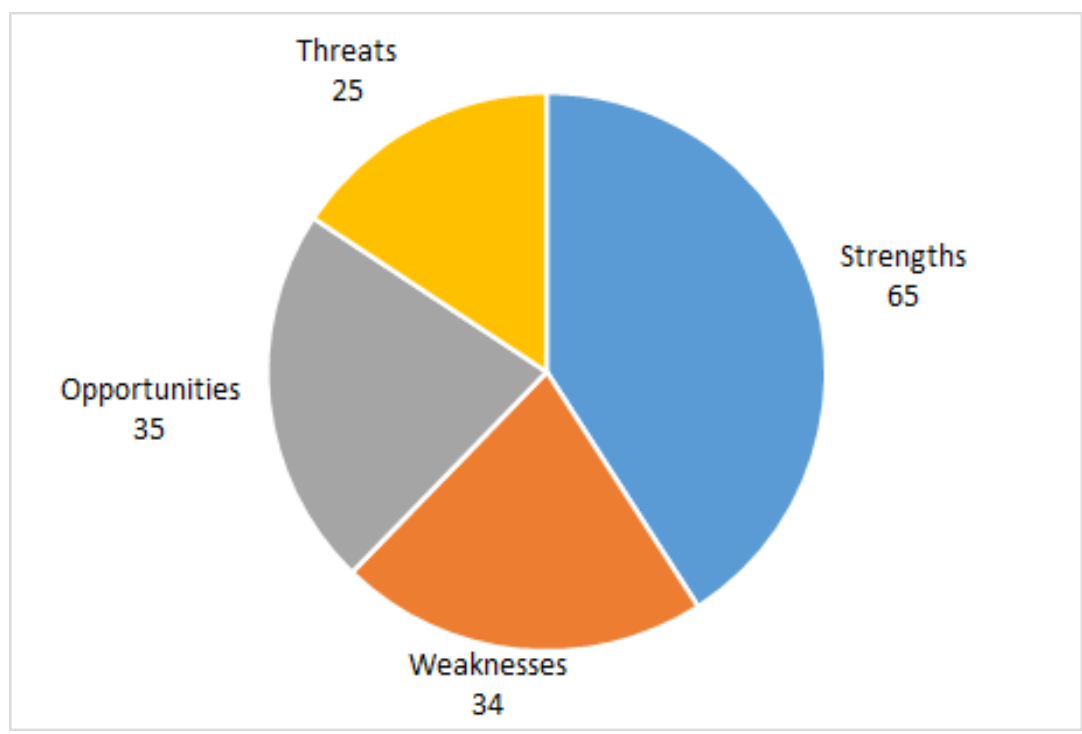

Figure 1. Number of subcategory occurrences in participant's contributions.

We found that the participants were optimistic about robotics and AI: they mostly highlighted the Strengths (65 occurrences in 8 subcategories) and Opportunities (35 occurrences in 9 subcategories) of these technologies. For example (Strengths, T2): "they are accepted and will be accepted because they are or will be convenient," or (Opportunities, T5): "The next step from here is an anthropomorphic-looking home aid who does all the house chores, up to indeed a romantic object of love, that is a robot who would be able and perform nearly all or all functions of a human companion in a romantic relationship. And here we cannot draw the line that it would perform the same functions as a human would, it could do so much more." The participants also discussed the Weaknesses of robotics and AI (34 occurrences in 9 subcategories), for example (T9): "It is true that when we have no previous experience, knowledge and imagination - then sometimes we lean on our biases, we will not develop new connections and meanings, we don't think about it, we avoid or ignore the need for something new." The Threats, associated with ETs, were brought out less frequently ( 25 occurrences in 5 subcategories), for example (T3): "On the other hand, using robots may lead to excess or waste, that is if they are implemented in places where it is not perhaps needed."

Secondly we examined how many different subcategories in each major category of meaning (Figure 2) were brought out by at least a quarter of the participants, allowing us to highlight the repeating patterns, and see how coherent was the knowledge about a particular category across the participants. The participants were more knowledgeable about the positive aspects of reviewed technologies. Both in the Strengths and Opportunities codes five subcategories were present in at least $25 \%$ of the participants' contributions, compared to three subcategories in Weaknesses and Threats. 


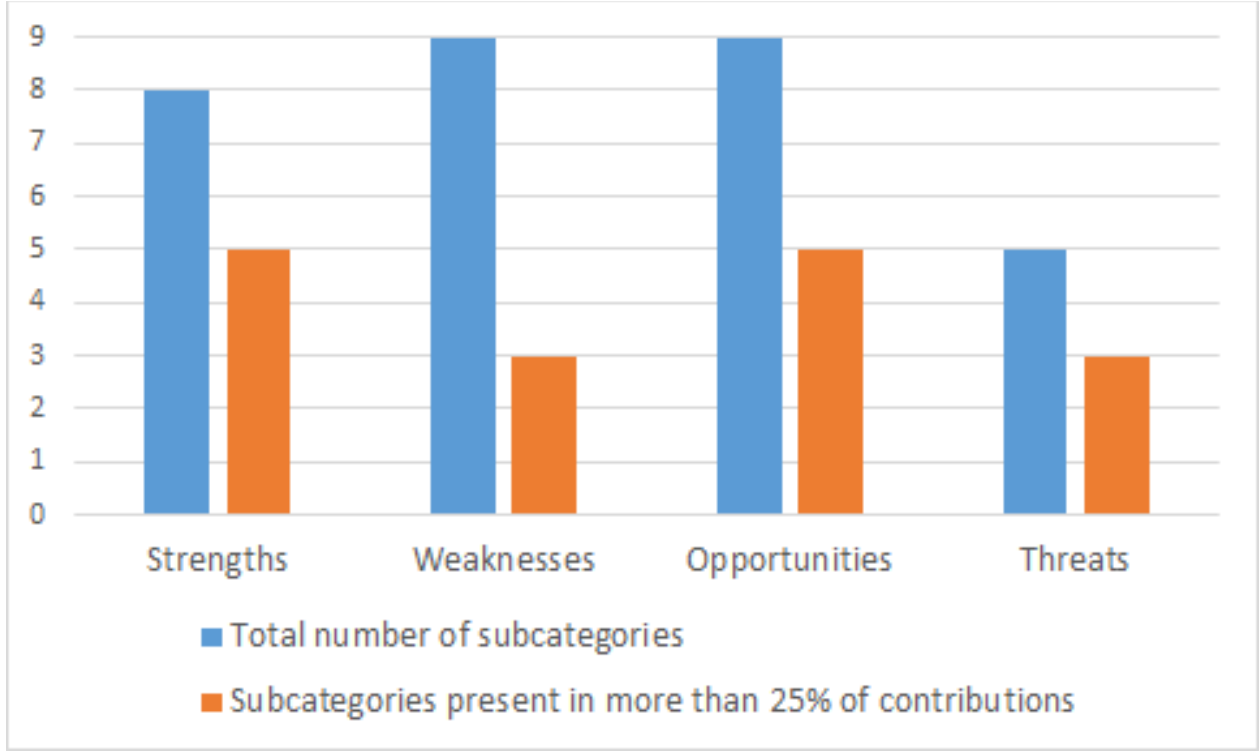

Figure 2. Number of subcategories in each major category.

The most used subcategories revealed certain areas of interest for the participants. In the Strengths category the subcategories "Support learning", "Support people in their work", and "Support people in their private lives" indicate that robots and AI are in the first place seen as tools that support people everywhere in their lives: "For example, many people have experienced the increase of quality time in their everyday lives when starting to use some automated tools or domestic robots. In the workplace robots can be given jobs that are dangerous or bad for human health" (T10). In the Weaknesses category, the common theme is that people do not have enough knowledge about robotics and AI and therefore need to be provided with specialized training courses: "because fresh discoveries have been left to professionals to make, it will take years before they become conveniently available to the wider public. /---/ reliability was a constant bottleneck, requiring a professional to be a key player in the solutions, or at least to be constantly present. There were and are so many technical problems that a pedagogue or philologist could be easily drowned in these when acting on their own" (T13). In the Opportunities category the prevalent topic is how robotics and AI can help to reshape society in unprecedented ways, change how we work and interact with each other: "we will be surrounded soon by different versions of intelligent systems that will assist us in every task; some of them will resemble our present ideas of what robots are, but some others will be radically different. This situation will necessarily require deep changes, both in society and in the robotics arena" (T2). This is something that can be seen as an advantage but also as an disadvantage as in the Threats category we also see how people are afraid of the changes that are introduced by robotics and AI: "This rapid increase in the number of robots causes some inconvenience and hesitation when considering people's daily income or the future of interpersonal relationships" (T16). Perhaps the most surprising issue is that with a few exceptions, the participants higher education teachers and their students - only scarcely described how robotics and AI could impact teaching and learning in higher education. In a way, this suggests that the participants have not really succeeded in associating the technologies with their everyday routines, indicating a need for training courses that would fill this gap.

\subsection{Perceptions of University Teachers, Related to Emerging Technologies}

Our second research question was "What are the perceptions of university teachers, related to emerging technologies?" Three common themes appeared from empirical material reflecting university teachers' perceptions on three levels: (a) on what and how ETs have been experienced; (b) how emergent technology might be used in light of beliefs and hope; and (c) what might using ETs mean as a future perspective. Below we present results from the thematic analysis, focusing mainly on three common themes which arise from the empirical material with the variations of subthemes: (a) expectations for use of ETs 
(subthemes: issues, aspects that need to be taken into consideration and future perspectives); (b) opportunities for use of ETs (subthemes: life and society, access and equality in education, university and schools, family, learning and learning support, role of educational robots); and (c) the future use of ETs (Figure 3). Those three common themes formed the common meanings of perceptions of university teachers related to ETs.

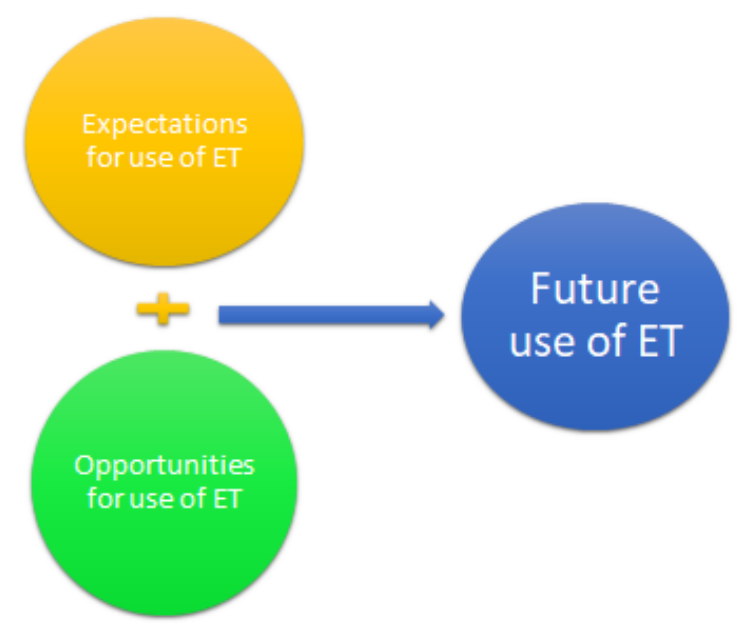

Figure 3. Common themes from thematic analyses.

\subsubsection{Theme 1: Expectation for use of emerging technologies}

For university teachers the use of ETs is related to relatively common expectations that refer to next subthemes, issues, aspects that need to be taken into consideration, and future perspectives:

- Issues: "There are several issues related to ETs and robots in education: difficulties for adapting robots to teaching curricula and vice versa; lack of expertise of present teachers in robotics and the ways to take advantage of them; lack of clear methodologies and guidelines regarding the systematic application of robotics..." (T1).

- Aspects that need to be taken into consideration: "There are aspects that need to be taken into consideration while this process takes place. The main one is probably that it is essential to improve the level of acceptance of robots within society" (T1).

- Future perspectives: "Future perspective related to robots concerns learning, teaching, interpersonal communication and requires rethinking and research based on the specifics of each subject and interdisciplinary integration" (T6).

\subsubsection{Theme 2: Opportunities for using emerging technologies}

From the analysis it appeared that theme opportunities for using ETs in higher education has more variation than the first theme and referred to the following subthemes: life and society, access and equality in education, university and schools, family, learning, and learning support, role of educational robots:

- Life and society: "In some ways we are already seamlessly becoming the robot's co-travelers. They have integrated so profoundly into our society, our way of life, that removing them from all of it would be nearly impossible" (T2).

- Equality in education: "What is certain is that the use of robotic devices will ensure better accessibility in education in the broadest sense, thus contributing to the creation of equal opportunities and the development of an inclusive society" (T5).

- Educational robots and learning: "The widespread use of educational robots or robotized toys will facilitate the new generations to become soon acquainted with robots. This intimacy with robots will necessarily sip into their families. Therefore, the number of people that will see robots as new useful devices will keep growing steadily..." (T1). "Augmented reality opens up unprecedented opportunities to experience objects and phenomena that are traditionally too far away or too tiny, it opens a new page in learning for learners with and without any special needs" (T5). 
- Learning support, and the role of educational robots: "The first role of educational robots is to raise awareness on the backstage of technology" (T14). "A robot, programmed to support learning, does not get tired or lose hope, does not express negative emotions, does not laugh at a pronunciation or grammar error, but notices successes, gives encouraging comments, discreetly points out mistakes or can support learners, especially if the learner needs more time to practice. The robot finds time for this and adjusts the content and speech tempo and speed to the learner accordingly. The robot allows us to play through a communication situation in a safe environment and can help provide more objective feedback than the student would be able to do" (T6). "Many other disciplines may benefit from robots if we see them as tools instead of end products. From art to healthcare, robots may solve numerous problems if we fit them into a systemic approach" (T14).

3.2.3. Theme 3: Future use of emerging technologies

The third main common theme, the future use of enhanced technology, appeared with variations of sub-themes (life and robots, use of robots, future with the robots, ethical and safety aspects about robot use, implication of ET in future education), and allowed us to construct a collective story about the future. Based on the dialogical approach introduced by [32] we constructed this story, using direct quotes from empirical material as empirical illustrations and basis for the story. To make this collective story coherent, we relied upon the structure of the text [35] (p. 438).

\subsubsection{Collective story of the future}

Robots are fast becoming a common phenomenon in everyday human life. When we look at human life from a broader perspective we can see robots being implemented into more and more spheres of life. If a person has always thought about himself and other significant humans in regards to all the different spheres of their life, then now these significant others can also originate from non-biological lifeforms.

In the future, the use of robots in educational activities will be even more of an application to develop social relationships and support teachers in language teaching. In the future, different technologies will be integrated and language learning robots will be able to process learning objectives. There are also many possibilities, different in purpose and combination, such as workshops, simulations, simulation experiments, discovery observations. I can't imagine everything yet...

Would it be possible to forecast what the future of robots could be like, departing from their past evolution? Very possibly yes: new developments are being produced constantly in basic disciplines such as AI, computer vision, speech, emotions or gesture recognition, mechatronics...We will be surrounded soon by different versions of intelligent systems that will assist us in every task; some of them will resemble our present ideas of what robots are, but some others will be radically different. This situation will necessarily require deep changes, both in society and in the robotics arena (again, in the broadest sense of the term robotics).

To do this, it is necessary to arouse interest in robotics already in kindergarten...It seems safe to ensure that in the future we will be surrounded by robots or similar machines or systems which will help us perform all sorts of tasks, and that this deployment will be easily accepted by society. As with any kind of previously conceived machine, there will be a learning period after which these systems will become most effective for each user. It is real hope that in the next decade, robotics tools will become everyday tools in kindergartens and schools as today every teacher has a computer.

It seems safe to believe that the following years will witness a dramatic influence of robots in our lives. In one way or another, many people will have to familiarize themselves with robot-assisted or robot-oriented jobs. Consequently, it is important that present day education takes this belief into consideration, preparing future citizens to be able to achieve maximum yield from robots.

In any case, like with other aspects of technology, ethical and safety aspects about robot use (again, in a wide sense) will have to be taken into consideration. But in a broader context, the development and use of robots has more implications than just diversifying learning and supporting learners and their learning. With new technology and the developments that come with it, there is a need to constantly learn and create new things. It is clear that we will need to learn how to take advantage of these devices, just like with any other man-made tool. And that implies at least a basic familiarity and understanding of the technology, its capabilities, and its shortcomings. This is one of the goals the Education system should pursue. 
We hope that this story might provoke critical discussions and some new changes or even ideas in the teaching and learning practice at the universities.

Finalising this subsection it is important to add that our findings demonstrate that university teachers have positive intentions, attitudes and common perceptions due to their previous experience related to using ETs which is similar to findings from previous studies [36].

\section{Discussion}

The aim of the paper was to gain a deep understanding of the university teachers' and their students' perceptions and points of view on ETs in their future life, their impact on society in general and particularly on their teaching practices. The focus in the empirical analysis was on the strengths, weaknesses, opportunities and threats of proliferation of ETs, and on the perceptions of university teachers related to ETs. Teachers' perceptions related to ETs appeared on three levels: on what and how ETs have been experienced, how emergent technology might be used in light of beliefs and hope and what might using ETs mean as a future perspective. The results of our research provide supporting evidence that previous experience related to ETs can support implementations and transformations in teaching and learning practices at the university.

One of the inherent characteristics of ETs is their novelty - in theory they have many promising features, but in practice it is difficult to estimate their true future success. In addition, ETs lack a well-developed user community or knowledge base about the best practices, as these are going to evolve concurrently with the spread of ETs. For these reasons, implementation of ETs may prove to be challenging.

Our findings showed that the teachers' perceptions related to ETs were based on general understanding of these technologies without going into the specifics of their teaching disciplines. In addition, the participants either had optimistic and positive expectations towards ETs or were accepting them as a part of the inevitable progress and teaching practice. It is possible that this is due to associating novel technologies with people's wellbeing [37-38]. The positive outlook on emerging technologies can also be caused by the already established correlation between having a previous experience with and more knowledge about a technology, and having more positive attitudes toward the technology $[15,20,21]$. This correlation has also been demonstrated in our earlier paper [39] that observed the change in attitudes of 16 higher education students after a 2-day workshop about AI-driven robots.

Based on findings it is evident that university teachers perceived the ETs as promising possibilities and were ready to implement them, possibly if ready-made solutions were available - while the discussion about the negative effects of ETs was insignificant. However, the scarce presence of negative aspects of ETs in participants' contributions could not really indicate that implementing ETs has no problems. According to [40], persons with inadequate knowledge about a technology are more likely to be influenced by so-called optimistic bias, an attitude that fades as the persons become more knowledgeable about the technology. The scarce presence of details in participants' visions regarding the integration of technologies with their disciplines leads us to suggest that the participants might have insufficient knowledge about the relationship between the practical realities of the technology and their discipline - explaining the optimistic bias. The teachers' difficulties of connecting technology with teaching practices have been also noted earlier in the literature (e.g. [41-42]). Addressing this deficiency requires a few approaches to be considered when introducing ETs to higher education teaching practices. Based on the findings it can be concluded that a combination of several interventions and developments is needed.

First, the principal responsibility for the successful and sustainable integration of ETs lies on initiators of the change - researchers, university teachers, policy-makers, administrators, and other stakeholders. The integration should be planned as a thorough process with all its stages and factors covered to maximum detail in order to become sustained in teaching practices (see also [43]). A particular focus should be on providing teachers with 
relevant training courses about the technology in question and ways of connecting it with the pedagogical goals. Secondly, as many teachers should be involved as possible in order to shape the best teaching practices that would work in "average classrooms operated by and for average students and teachers" [44]. Large participation could also ensure forming a functional support community, and, by using the co-creation approach, the development of efficient teaching and learning artefacts while improving the adoption of ETs [45].

Considering that already today in some domains people trust emerging technologies more than humans [17], even though these technologies have been around for a little time only, it is crucial for the future developments that people are given thorough knowledge about the possibilities and limitations of the technologies that lead their lives. Higher education, and education in general, is particularly responsible for this to happen: "we will need to learn how to take advantage of ET just like with any other man-made tool. And that implies at least a basic familiarity and understanding of the technology, its capabilities, and its shortcomings. This is one of the goals the education system should pursue" (T1).

\section{Limitations and Future Directions}

In this paper we examined the written and recorded visions from 18 university teachers and students who had previously taken part in a specialized program about AI and robotics. The quality of the collected data could have been improved by increasing the sample size, including persons without previous training about this area (but also, as a control group, persons with deeper knowledge base about this area), and involving a wider variety of ETs. In addition, semi-structured interviews could have been more suitable for collecting more detailed empirical data. Future research in this field could focus on teachers' understanding about the connections between ETs and their field of teaching. It is possible that such studies should include a pre-study training in order the university teachers would be able to better evaluate the ETs in the context of their teaching practices.

\section{Supplementary Materials:}

Figure 1: Number of subcategory occurrences in participant's contributions. Each subcategory was counted once. Figure 2: Number of subcategories in each major category. Figure 3: Common themes from thematic analyses. Table 1: Categories of meanings and subcategories.

\section{Author Contributions:}

Conceptualization: Janika Leoste and Larissa Jõgi; Methodology: Janika Leoste and Larissa Jõgi; Validation: Tiia Õun and Luis Pastor; Formal Analysis: Janika Leoste and Larissa Jõgi; Investigation: Janika Leoste; Resources: Janika Leoste; Data Curation: Janika Leoste; Writing - Original Draft Preparation: Janika Leoste, Larissa Jõgi, Tiia Õun, Jose San Martin Lopez; Writing: Janika Leoste, Larissa Jõgi, Luis Pastor, Tiia Õun; Visualization: Janika Leoste and Larissa Jõgi; Supervision: Janika Leoste, Indrek Grauberg; Project Administration: Janika Leoste; Funding Acquisition; Tiia Õun.

\section{Funding:}

The article processing charges were funded by the School of Educational Sciences, Tallinn University.

\section{Data Availability Statement:}

Informed consents were gathered from all subjects involved in the study.

\section{Data Availability Statement:}

The data that was used in this study is available at: https://drive.google.com/drive/folders/1qA7g6TjwFEXq6t0iP-Zv7pP7TC0LSnhE?usp=sharing

\section{Conflicts of Interest:}

The authors declare no conflict of interest.

\section{References}


1. Oliveira, A.; Behnagh, R.F.; Ni, L.; Mohsinah, A.A.; Burgess, K.J.; Guo, L. Emerging technologies as pedagogical tools for teaching and learning science: A literature review. Human Behavior and Emerging Technologies 2019, 1, 149-160.

2. Elliott, S.W. Computers and the Future of Skill Demand. OECD Publishing: Paris, 2017. https://doi.org/10.1787/9789264284395-en

3. Rotolo, D.; Hicks, D.; Martin, B. What is an emerging technology? Research Policy 2015, 44(10), 1827-1843. https://doi.org/10.1016/j.respol.2015.06.006

4. $\quad$ OECD. The future of education and skills. Education 2030. OECD: Paris, 2018.

5. Verbeek, P.P. (2001). Don Ihde: The technological lifeworld). In American philosophy of technology: The empirical turn; Achterhuis, H., Ed.; Indiana University Press: Bloomington, 2001; pp. (119-146).

6. Crieghton, J. Today, Michio Kaku described what life will look like in twenty years. Futurism 2018, Available online: https://futurism.com/michio-kaku-life-20-years-future/ (accessed 2507 2021)

7. Joint Information Systems Committee. Horizons report on emerging technologies and education. JISC: Bristol, England, 2019.

8. Visvizi, A.; Lytras, M.D.; Sarirete, A. Emerging Technologies and Higher Education: Management and Administration in Focus. In Management and Administration of Higher Education Institutions at Times of Change; Visvizi, A., Lytras, M.D., Sarirete, A., Eds.; Emerald Publishing Ltd: Bingley, 2019; pp. 1-11. https://doi.org/10.1108/978-1-78973-627-420191001

9. Mavroudi, A.; Papadakis, S. A Case Study on How Greek Teachers Make Use of Big Data Analytics in K-12 Education. In Emerging Technologies for Education. SETE 2019; Popescu, E.; Hao, T.; Hsu, T.C.; Xie, H.; Temperini, M.; Chen, W., Eds.; Springer: Cham., 2020. https://doi.org/10.1007/978-3-030-38778-5 1

10. Reyes, J.A. The skinny on big data in education: learning analytics simplified. TechTrends 2015, 59(2), 75-80.

11. Cook, V.S.; Gregory, R.L. Emerging technologies: It's not what you say - it's what they do. Online Learning 2018, 22(3), 121-130. https://doi.org/10.24059/olj.v22i3.1463

12. Grimus, M. Emerging Technologies: Impacting Learning, Pedagogy and Curriculum Development. In Emerging Technologies and Pedagogies in the Curriculum. Bridging Human and Machine: Future Education with Intelligence; Yu, S., Ally, M., Tsinakos, A., Eds.; Springer: Singapore, 2020. https://doi.org/10.1007/978-981-15-0618-5 8

13. Niederhauser, D.S.; Howard, S.K.; Voogt, J.; Agyei, D.D.; Laferriere, T.; Tondeur, J.; Cox, M.J. Sustainability and Scalability in Educational Technology. Technology, Knowledge and Learning 2018, 23, 507-523. https://doi.org/10.1007/s10758-018-9382-z

14. Varghese, N.V.; Mandal S. Teaching-Learning and New Technologies in Higher Education: An Introduction. In Teaching Learning and New Technologies in Higher Education; Varghese, N.V.; Mandal, S., Eds.; Springer: Singapore, 2020. https://doi.org/10.1007/978-981-15-4847-5 1

15. euRobotics AISBL. Robotics 2020 - Strategic Research Agenda for Robotics in Europe. Years 2014-2020. SPARC: Brussels, 2015.

16. Clarke, R. Principles and business processes for responsible AI. Computer Law \& Security Review 2019, 35(4), 410-422.

17. Oracle; Savanta. Money and Machines: 2021 Global Study. Oracle Corporation, 2021. Available online: https://www.oracle.com/a/ocom/docs/applications/erp/money-and-machines-report-2021.pdf (accessed 2507 2021).

18. Wisskirchen, G.; Biacabe, B.T.; Bormann, U.; Muntz, A.; Niehaus, G.; Soler, G.J.; von Brauchitsch, B. Artificial intelligence and robotics and their impact on the workplace. IBA Global Employment Institute: London, 2017.

19. United Nations. World Economic and Social Survey 2018. United Nations: New York, 2018.

20. Leite, I.; Martinho, C.; Paiva, A. Social robots for long-term interaction: a survey. International Journal of Social Robotics 2013, 5(2), 291-308.

21. Turja, T.; Van Aerschot, L.; Särkikoski T. Finnish healthcare professionals' attitudes towards robots: reflections on a population sample. Nursing Open 2018, 5(3), 300-309.

22. Venkatraman, N. IT-enabled business transformation: from automation to business scope redefinition. Sloan Manage 1994, 35, 73-87.

23. Rogers, P.L. Barriers to Adopting Emerging Technologies in Education. Journal of Educational Computing Research 2000, 22(4), 455-472.

24. Davenport, T.H. Process management for knowledge work. In Handbook on Business Process Management 1, 2nd ed.; vom Brocke, J., Rosemann, M., Eds.; Springer: Heidelberg, 2015; pp. 17-35. https://doi.org/10.1007/978-3-642-45100-3 2

25. Haridusvaldkonna arengukava 2021-2035. (2020). Haridus- ja Teadusministeerium. Tallinn. Available online: https://www.hm.ee/sites/default/files/eesti haridusvaldkonna arengukava 2035 seisuga 2020.03.27.pdf (accessed 25 07 2021)

26. Li, L.Y. Exploring the Use of Focused Freewriting in Developing Academic Writing, Journal of University Teaching $\mathcal{E}$ Learning Practice 2007, 4(1), 41-53.

27. Finlay, L. Debating phenomenological research methods. Phenomenology and Practice 2009, 3(1), 6-25.

28. Braun, V.; Clarke, V. Using thematic analysis in psychology. Qualitative Research in Psychology 2006, 3, 77-101. https://doi.org/10.1191/1478088706qp063oa

29. Marton, F. Phenomenography - A research approach investigating different understandings of reality. Journal of Thought 1986, 21(2), 28-49.

30. Benjamin, S. When Plan A Falls Through: Using a Collective Story Methodology to Construct a Narrative. In Proceedings of the TTRA International Conference, Vail, Colorado, 15-17 June, 2016.

31. Saldana, J. The Coding Manual for Qualitative Researchers. SAGE Publications Inc.: London, 2009.

32. Frank, A.W. Letting Stories Breathe: A Socio-Narratology. University of Chicago Press: Chicago, IL, 2010.

33. Saltmarshe, E. Using Story to Change Systems. Stanford Social Innovation Review 2018.

34. Nowell, L.; Norris, J.; White, D.; Moules, N. Thematic Analysis: Striving to Meet the Trustworthiness Criteria. International Journal of Qualitative Methods 2017, 16, 1-13. 
35. Jõgi, L.; Karu, K. Nordic-Baltic cooperation in adult education: a collective story of Estonian adult educators. International Review of Education 2018, 64, 421-441.

36. Scherera, R.; Teo, T. Unpacking teachers' intentions to integrate technology: A meta-analysis. Educational Research Review 2019, 27, 90-109.

37. Riva, G. What is positive technology and its impacts on cyberpsychology. Stud Health Technol Inform 2012, 181, 37-41.

38. Grossi, G.; Lanzarotti, R.; Napoletano, P.; Noceti, N.; Odone, F. Positive technology for elderly well-being: A review. Pattern Recognition Letters 2020, 137, 61-70.

39. Leoste, J.; Viik, T.; San Martín López, J.; Kangur, M.; Vunder, V.; Mollard, Y.; Õun, T.; Tammo, H.; Paekivi, K. Robots as my future colleagues: changing attitudes towards collaborative robots by means of experience-based workshops. In Smart Innovation, Systems and Technologies: 6th conference on Smart Learning Ecosystems and Regional Development (SLERD 2021); Mealha. O., Dascalu, M., Di Mascio, T., Eds.; Springer: Singapore, 2021.

40. Hewitt, B.; White, G.L. Optimistic Bias and Exposure Affect Security Incidents on Home Computer. Journal of Computer Information Systems 2020. https://doi.org/10.1080/08874417.2019.1697860

41. Naidaam, J. Transforming the Classroom Context. Mathematics Teachers' Experiences of the Use of Technology-Enabled Pedagogy for Embracing the Fourth Industrial Revolution. Teaching and Learning in the 21st Century 2021, 6, 71-86.

42. Angeli, C.; Valanides, N. Epistemological and methodological issues for the conceptualization, development, and assessment of ICT-TPCK: advances in technological pedagogical content knowledge (TPCK). Computers Education 2009, 52(1), $154-168$.

43. Leoste, J.; Heidmets, M.; Ley, T.; Stepanova, J. Classroom Innovation Becoming Sustainable: A Study of Technological Innovation Adoption by Estonian Primary School Teachers. IxDEA Interaction Design E Architecture(s) 2021, 42, 144-166.

44. Brown, A.L. Design experiments: theoretical and methodological challenges in creating complex interventions in classroom settings. Journal of the Learning Sciences 1992, 2(2), 141-178.

45. Rodríguez-Triana, M.J.; Prieto, L.P.; Ley, T. et al. Social practices in teacher knowledge creation and innovation adoption: a large-scale study in an online instructional design community for inquiry learning. International Journal of Computer-Supported Collaborative Learning 2020, 15, 445-467. https://doi.org/10.1007/s11412-020-09331-5 